\title{
TEAM Chapman: Lessons From Community Building
}

\author{
Mary Portis ${ }^{1}$, Somai Sayavong ${ }^{2}$, Phouvieng Savangsy ${ }^{2}$, Sonia Robles ${ }^{2}$, \\ Woody Hosler ${ }^{2}$, Darcia Johnson ${ }^{2}$ \\ California State University, Chico ${ }^{l}$ \\ TEAM Chapman ${ }^{2}$
}

\begin{abstract}
Organizations that wish to impact community health have better participation and outcomes if time is spent doing community building activities. This article showcases several community building activities that helped a low income, culturally diverse community come together to improve their health.

(C) 2003 Californian Journal of Health Promotion. All rights reserved.

Keywords: TEAM Chapman, community building, outreach, CSU Chico
\end{abstract}

\section{Introduction}

TEAM Chapman is a youth-driven, communitybased organization developed in 1997 to improve the social, physical and environmental health of residents in a low income, culturally diverse neighborhood called Chapman. TEAM Chapman was funded from 1997 to 2002 by The California Wellness Foundation through its Children Youth Community Health Initiative (CYCHI). This initiative focused on engaging children, youth and adults in the transformation of their social, physical and chemical environments. With this funding, children, youth and adults formed partnerships to work together to help the community, with youth taking on meaningful decision-making and leadership roles. This article reports on some of the successes of those first years.

\footnotetext{
About Chapman

Chapman is a distinct neighborhood of about 3000 residents within a city of 100,000 . It is a low income, ethnically diverse neighborhood within a larger, higher income, higher educated, Caucasian community. To residents of the city, the name Chapman is synonymous with danger, violence, poverty, substance abuse and gangs. Some issues do exist in Chapman, but much of its notoriety is a product of years of discrimination, prejudice, and urban myth.
}

\section{The Beginning}

In 1997, groups of volunteer community members gathered to discuss concerns, identify needs and assets, develop objectives, and plan how the residents could work together to improve the health of the community. A volunteer board was formed from the residents who were willing to make a multiple-year commitment to the organization. Funding was sought and acquired. A paid work force composed of a young program director and three youth organizers ages 17,18 and 19 were hired. Several other youth organizers were added after year two. The employees represented the major ethnic groups in the community (AfricanAmerican, Laotian, Thai, Mexican, Hmong and Caucasian). Two community partners were added: a professor from California State University, Chico to act as the Academic Support Coordinator and the Director of Big Brothers Big Sisters to act as a lead in mentoring.

\section{The Mission}

One of the first activities of TEAM Chapman was developing a mission statement using input from the community as a whole. The mission is stated as: "to provide for the well-being of all in our community through services, healthy activities and to encourage one another with random acts of kindness." 


\section{The Need}

Through focus groups, surveys, and archival data the community consistently voiced a need to reduce violence, substance abuse and negative influences on youth. They felt the needs would best be met through the provision of positive, healthy alternatives for youth. While healthier activities, and thus healthier bodies, healthier social climate and a healthier environment seemed like the natural place to begin working, it was quickly discovered that no success could be achieved without cohesiveness between the residents. The neighborhood had no formal community networks and the informal networks were divided into subgroups. The community's major cultural groups (i.e., Mexican, Laotian, Hmong, Caucasian, Native American, African American) rarely interacted with each other. Youth rarely interacted with the adults in their own ethnic group and were especially separate from adults in other ethnic groups. To overcome the divisions between the residents, community building interventions were implemented separately and in conjunction with healthoriented activities. Those activities that became a part of the community's yearly rituals and daily life are highlighted here.

\section{Peace Garden}

TEAM Chapman's office building is a small house that was abandoned and in disrepair. When TEAM Chapman moved in, much work was needed to make it habitable. Volunteers gathered to clean, paint and fix, which created a functional shelter (Figure 1 and Video Clip 1), but the yard was strewn with rocks and weeds and garbage. The idea of a community garden, later named the Peace Garden, was introduced by a board member. Community youth volunteered countless hours clearing the land and then landscaping a garden that was not only a fertile planting space, but a space that continued to communicate the importance of community and diversity and participation.

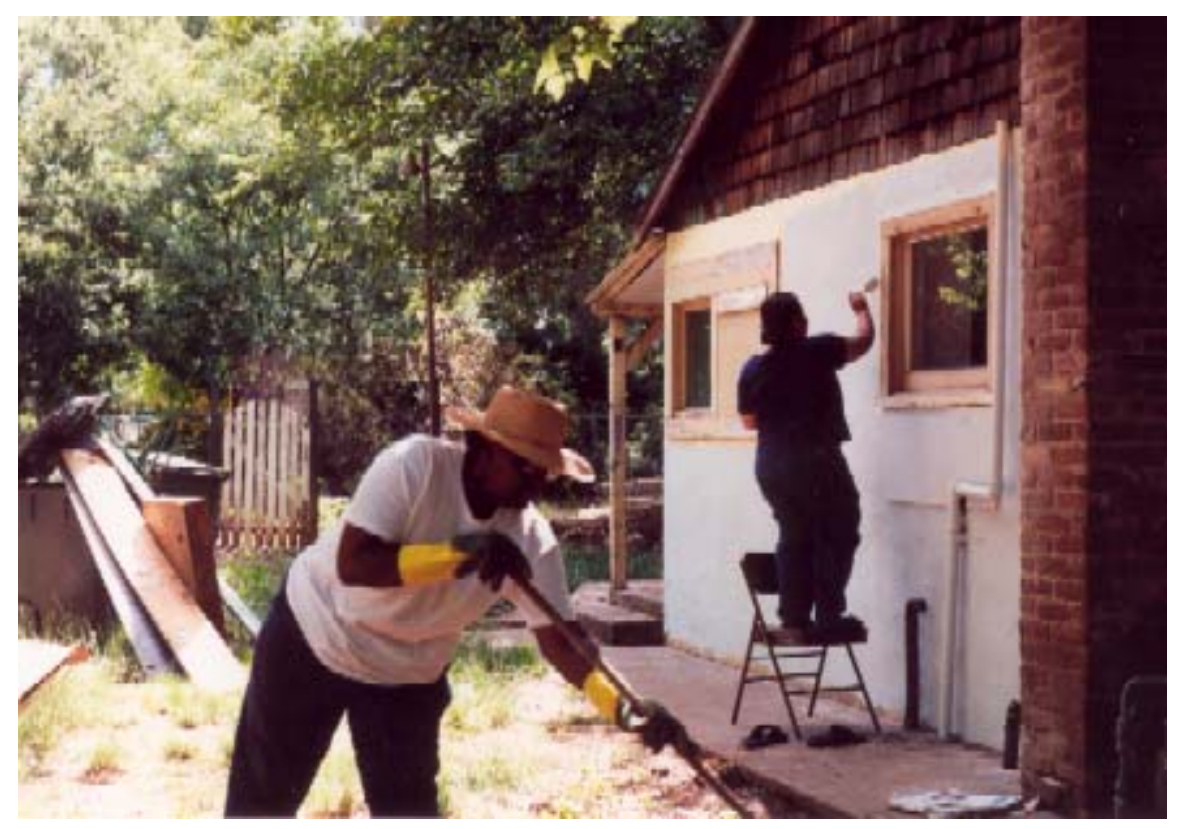

Figure 1

Office Repair 
The center of the garden is a circle filled with colorful flowers. A walkway surrounds the center and branches off in four directions. In between each branching walkway is a segment of the garden devoted to growing vegetables indigenous to four of the ethnic groups (i.e.,
Mexican, Native American, African American, Southeast Asian) represented in Chapman. As a living thing, the garden requires constant attention from community members and provides a food commodity that can be shared.

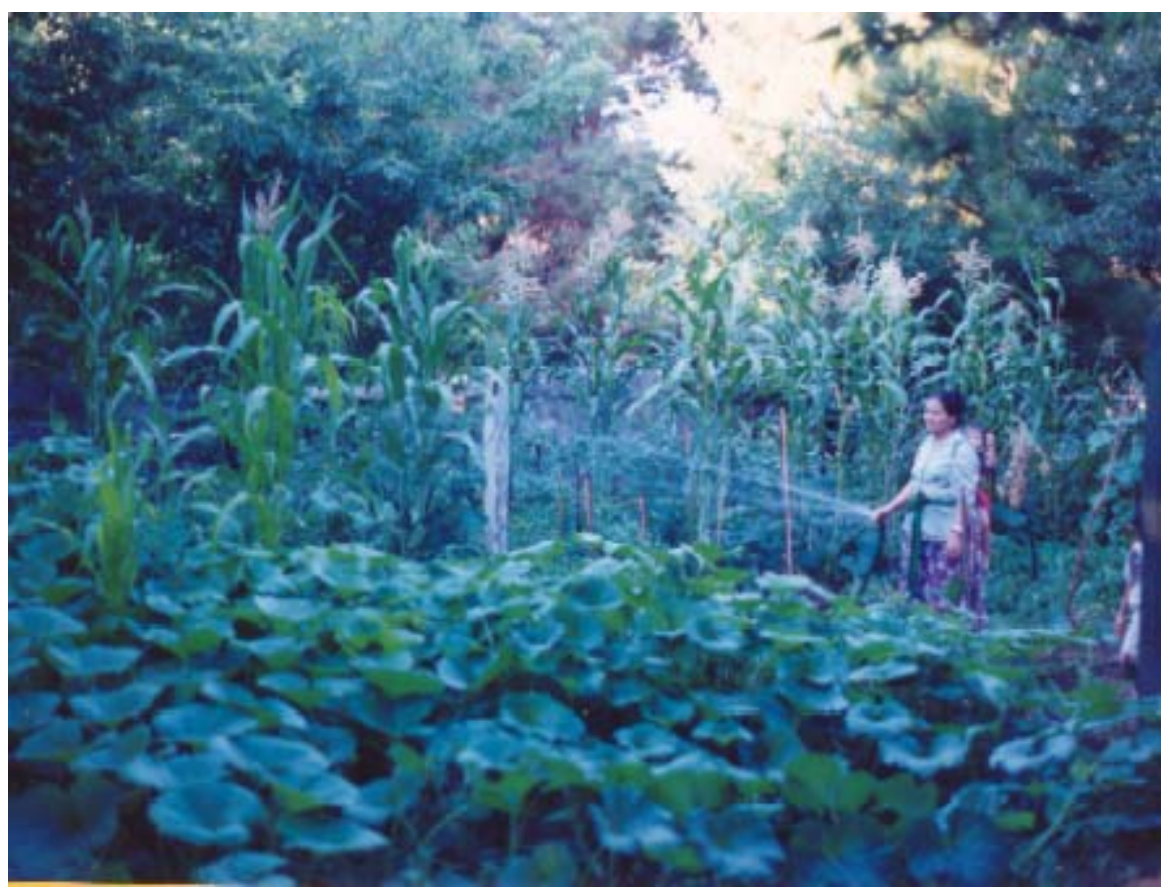

Figure 2

Peace Garden in Bloom

To further involve the residents, a stepping stone project was initiated. Two hundred 12 inch cement squares, ready-mix, thin set and hundreds of pounds of colored ceramic tiles were donated by various local businesses. Children, youth, adults and elders from the community came to the office building and created unique, colorful stepping stones (Figure $3 \&$ Video Clip 2). Some of the stones were used to create a patio where tables and chairs could be set out for meetings and activities. The rest of the stones were used to create a tiled fire pit that could seat twenty people (Figure $4 \&$ Video Clip 3). Making the stepping stones was an engaging activity for most people and the finished product was beautiful regardless of artistic ability. Residents of all ages pointed out their stepping stone to friends. Many of the children cleaned off their personal stepping stone whenever they attended an activity. 


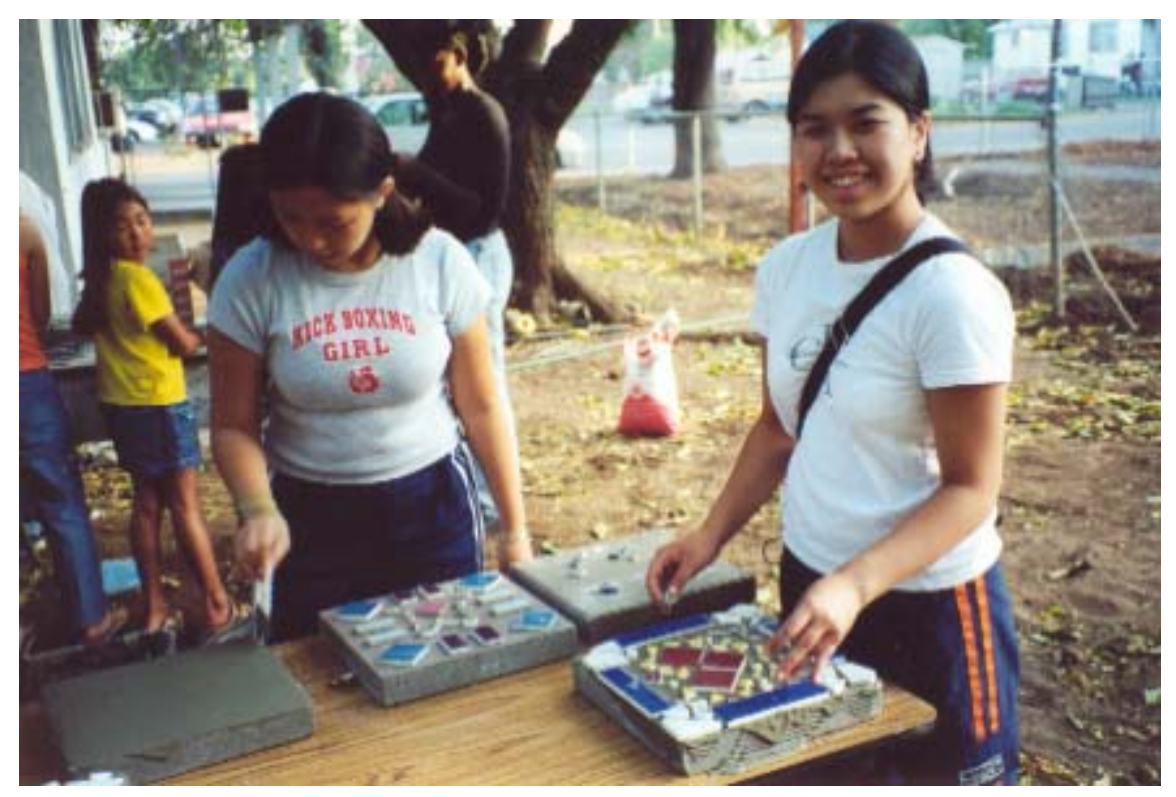

Figure 3

Making of the Stepping Stone

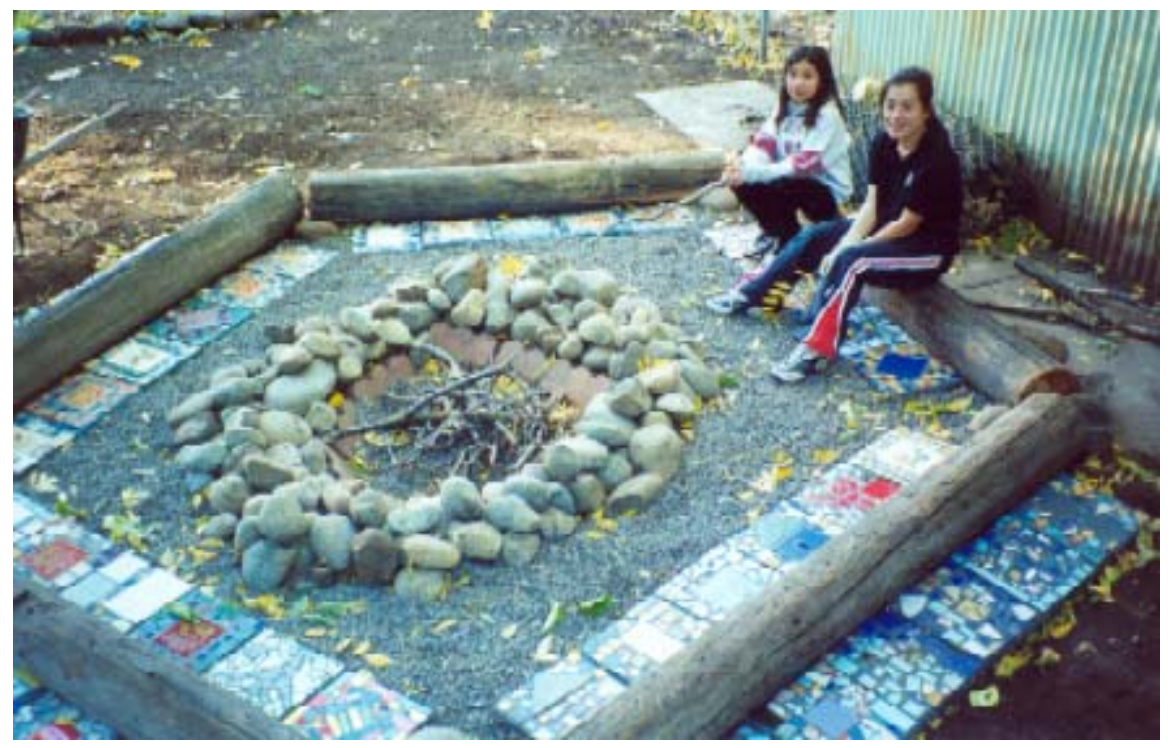

Figure 4

Fire Pit

Through its time intensive nature, the large number of volunteers (over 300) and the visual reinforcement of seeing change take place, the Peace Garden became a focal symbol of community building. In addition, the garden served as a model to others who wished to enhance their surroundings.

\section{Community Clean Up}

Litter, old cars, discarded refrigerators, tires, garbage, and broken furniture were just some of the items scattered liberally throughout the yards and streets of Chapman. Dump fees were blamed for much of the trash accumulation. Apathy and lack of pride were also listed as 
reasons. Starting with year one, TEAM Chapman organized a day where residents of all ages could come together and cart away the trash. Industrial sized dumpsters were parked in an accessible spot and residents could dump as many loads of trash as they had for a full eight hour day, for free. For elderly or disabled residents without a means to haul their trash, volunteers with trucks picked up, packed and delivered the trash to the dumpsters. Child volunteers in teams of five to eight were paired with a college student, assigned a set of streets on a map, and sent to collect trash (Figures 5 \& 6). Throughout the day, the filled dumpsters were picked up and replaced with empty ones by the local waste management company. In year three, a small fee was charged to use the dumpsters but the number of residents using the service still increased.

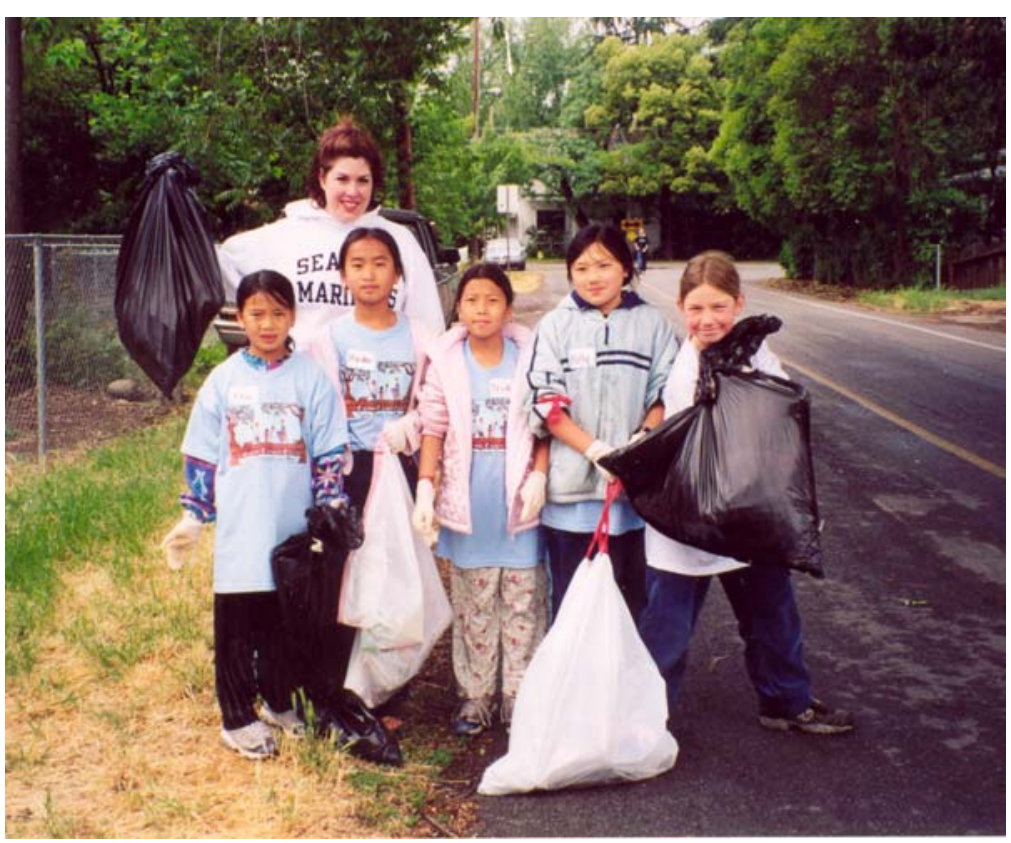

Figure 5

Child Trash "Picker Uppers"

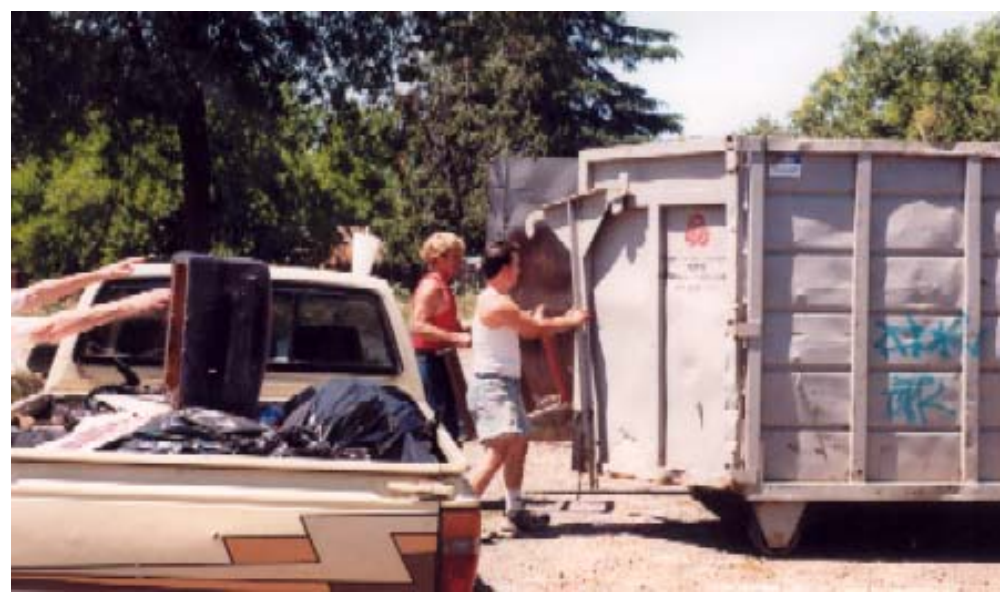

Figure 6

"Dumpster Boys" 


\section{Annual Multi-Cultural Events}

Each fall a multicultural night of food and entertainment was presented to the community by residents who wished to sing, dance, cook, or share the artistry of their ethnic group. In the first year, over twenty volunteers cooked their favorite ethnic dishes for residents to sample, and fifteen different talents were showcased in a program (Figures $7 \& 8$, Video Clip 4). As the years progressed more residents were willing to share their talents and special foods. In addition to multi-cultural night, TEAM Chapman sponsored other community-wide programs such as car shows, Dia Del Campesino, National Night Out Against Crime and canned food drives.

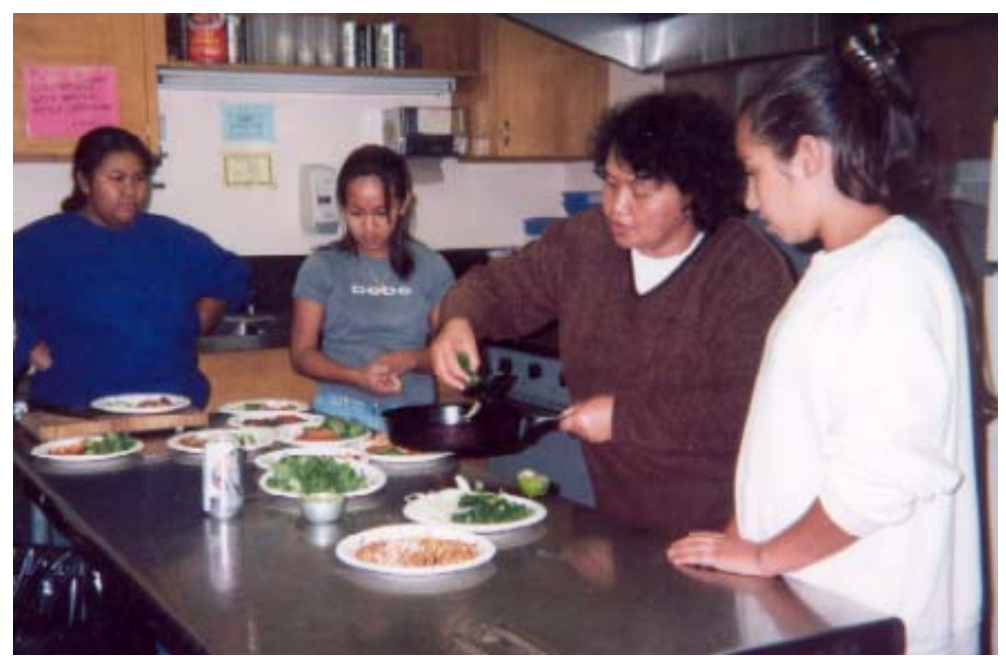

Figure 7

Community Residents Cooking Together

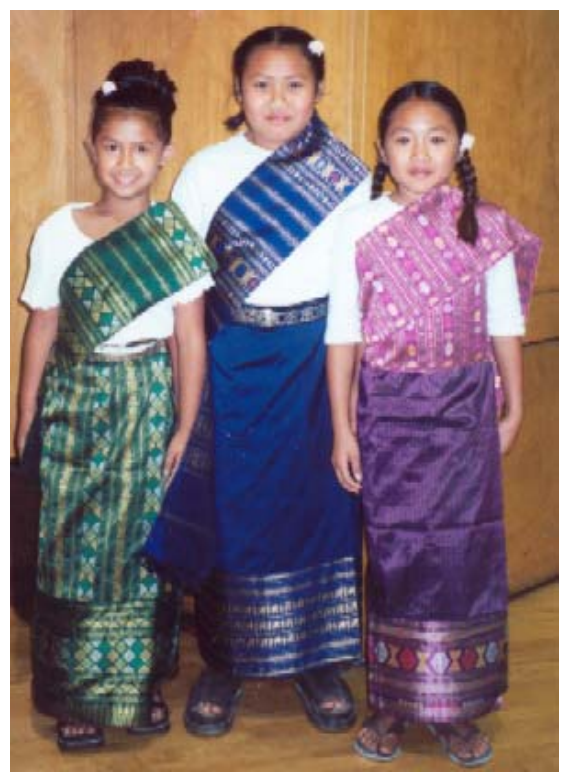

Figure 8

Girls in Traditional Laotian Dress 


\section{Signs of Health}

To enhance awareness of environmental issues a visual arts activity was offered to the community. Everyone was invited to come to TEAM Chapman to paint environmental messages on four foot square pieces of pressboard. Suggestions for messages were provided but community members decided on the final messages and graphics. In all, 139 children, youth and adults participated. The participants created a wide range of messages that presented environmental philosophy, cultural beliefs, and actions everyone can take to improve the environment (Figures $9 \& 10$ ). The signs were displayed at a community wide health fair and celebration and then found more permanent placements at different sites around the community.

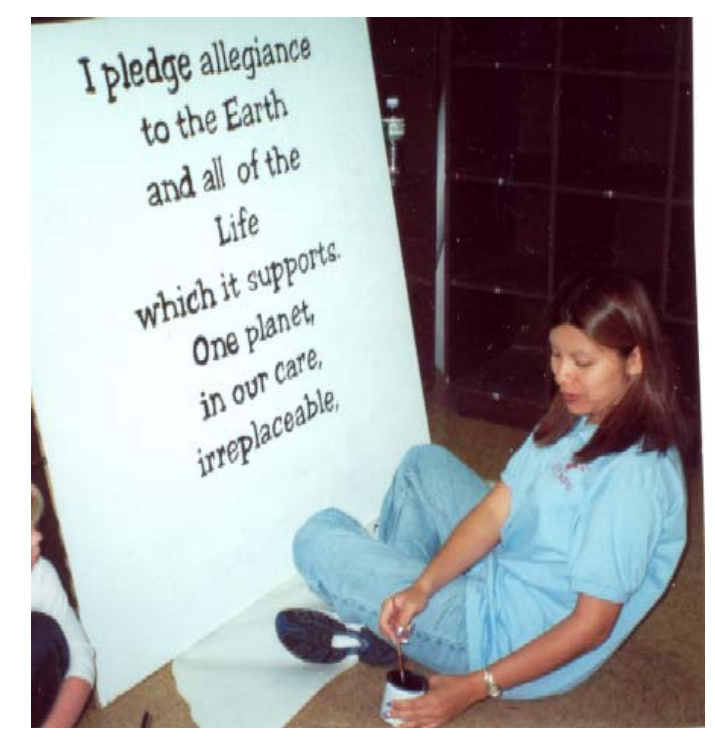

Figure 9

Girl painting environmental pledge.

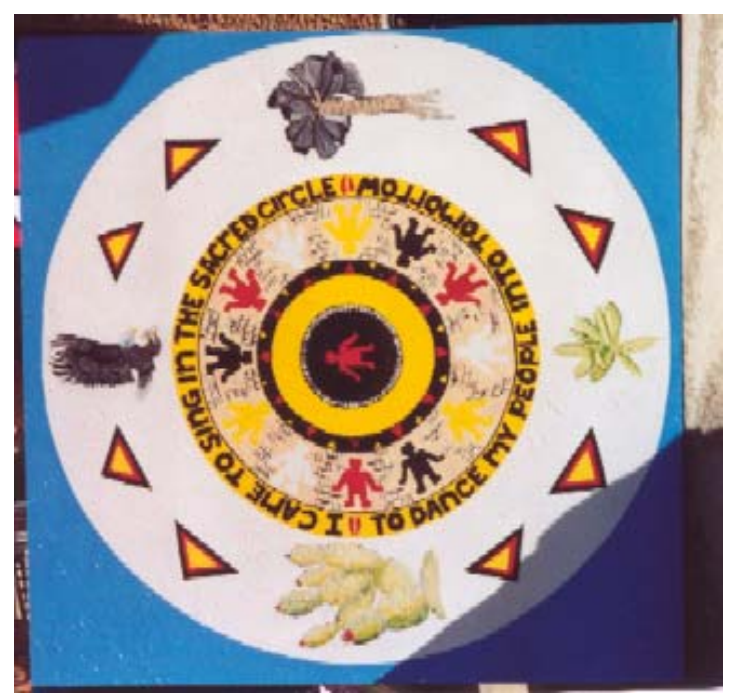

Figure 10

Native American environmental message. 


\section{Faces of Chapman}

Faces of Chapman is a book of nearly one hundred photographs and personal stories of Chapman residents. Children, youth and adults volunteered their talents to research, write, interview and take photographs (Figure 11). The project was started to build relationships within the community. As the work was completed the book, became a source of pride for the community and a way to communicate the community's strengths and identity to outsiders. Newspapers, television, and formal leaders in the larger community recognized the efforts in the Faces of Chapman project and their attention furthered community pride and cohesiveness.

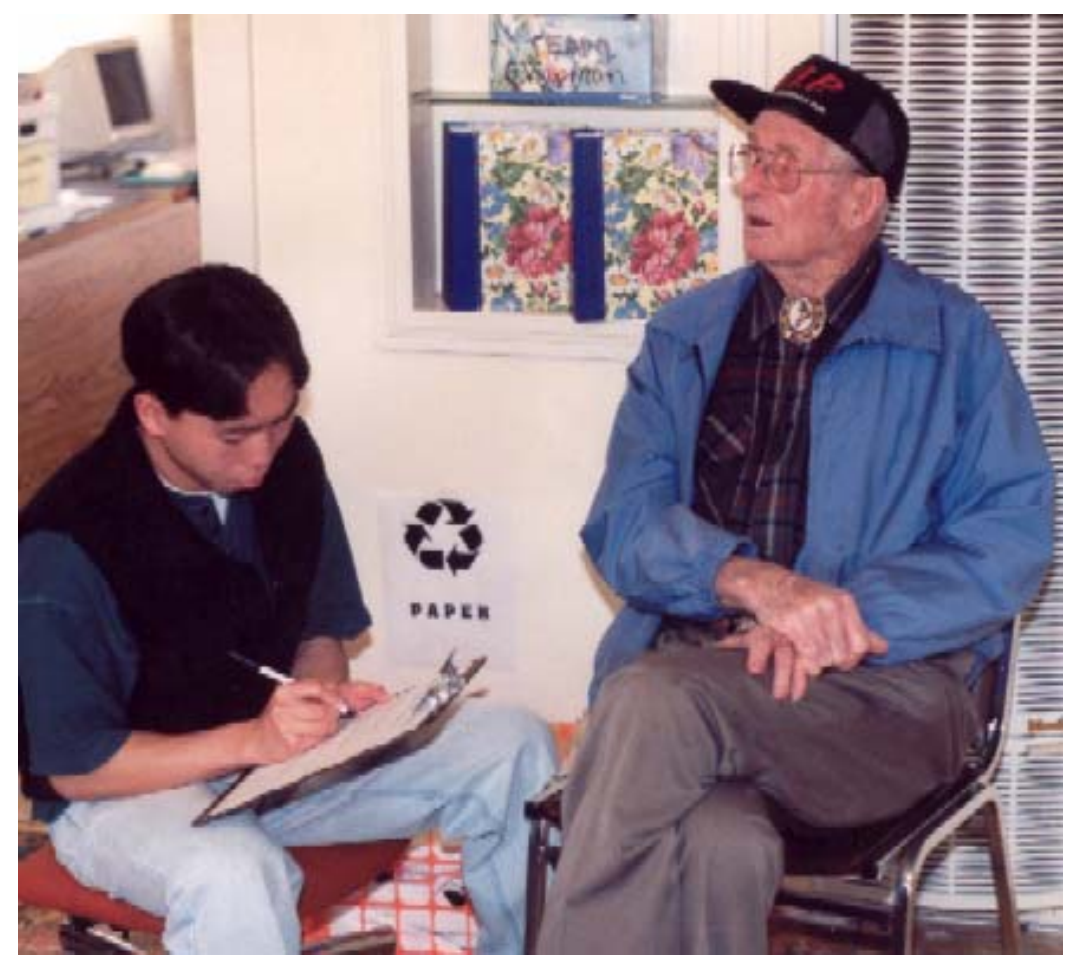

Figure 11

Faces of Chapman.

\section{Summary}

When TEAM Chapman started, most of the volunteers were focused on providing programs directed toward specific health problems and conditions. No one anticipated the need for, or the positive impact of, community building interventions. Every volunteer now understands that strong community networks and relationships among residents translate into residents taking pride in their environment and taking personal participatory action in protecting that environment and the people with which they share that environment. Every time an individual participates with the community, that individual increases his or her own capabilities. Those capabilities contribute to community competency. By starting with community building interventions, groups can create a powerful, resilient, competent workforce so that the specific health goals can be achieved. 


\section{References}

Big Brothers and Big Sisters of Butte County. (2003). Home page. Retrieved February 7, 2003, from http://www.bigbrothersister.org/

California State University, Chico. (2003). Home page. Retrieved February 7, 2003, from http://www.csuchico.edu

TEAM Chapman. (2003). Home page. Retrieved February 7, 2003, from http://bcoe.butte.k12.ca.us/ess/chap/

The California Wellness Foundation. (2003). Home page. Retrieved February 7, 2003, from http://www.tcwf.org/

\section{Acknowledgements}

This project was funded by The California Wellness Foundation Grant \# 9900215 "TEAM Chapman Wellness Village", and the California State University, Chico, College of Behavioral and Social Sciences and the Department of Health and Community Services. The authors would like to thank the following organizations and individuals who have made a significant contribution to the success of the TEAM Chapman Project:

\section{Butte County Office of Education}

TEAM Chapman Community Board Members

Jane Dolan, Butte County Supervisor

California State University, Chico, Health and Community Services Department

Big Brothers Big Sisters

Chapman Elementary School

Four Winds of Indian Education

Community Collaborative for Youth

Parent Education Network

Dorothy F. Johnson, CARD Center

P.A.C.E. Parent and Child Education Center

Mr. Mark Hooper

Mr. Rudy Griscombe

Ms. Jane Dolan, Butte County Supervisor

Community Collaborative for Youth

Hundreds of community volunteers

Author Information: CSU Chico

Mary Portis, DrPH

Professor

Department of Health and Community Services

California State University, Chico

Author Information: TEAM Chapman

Somai Sayavong, Director, TEAM Chapman

Phouvieng Savangsy, Youth Organizer

Sonia Robles, Youth Organizer

Woody Hosler, Youth Organizer

Darcia Johnson, Past Director, TEAM Chapman 